\title{
Sorption behaviour of diuron under a mediterranean climate
}

\author{
Xavier LOUCHART ${ }^{\mathrm{a} *}$, Bernd LENNARTZ ${ }^{\mathrm{b}}$, Marc VOLTZ \\ ${ }^{a}$ Laboratory on Interactions between Soil, Agrosystem and Hydrosystem (LISAH), National Institute for Agricultural Research (INRA), 2 place Viala, \\ 34060 Montpellier Cedex 1, France \\ ${ }^{\mathrm{b}}$ Institute of Soil Science and Plant Nutrition, Rostock University, Justus-von-Liebig-Weg 6, 18051 Rostock, Germany
}

(Accepted 10 December 2004)

\begin{abstract}
The assessment of field-like sorption behaviour is critical to predict the fate and transport of organic compounds, especially when long time periods are considered. We compared field-derived sorption isotherms for diuron from a 4-year database collected in a Mediterranean catchment with adsorption and desorption isotherms from classical batch studies. In addition, a new technique of drying the slurry samples inbetween various desorption steps was applied in order to reflect the recurrent drying of the topsoil under Mediterranean climate conditions. Our results show first that the field-derived isotherms indicated a larger sorption capacity of the soil at small diuron concentrations (larger Kf and smaller exponent for the Freundlich parameters) than those derived from standard batch experiments. Second, when the soil was dried before desorption, chemical release was reduced by up to $29 \%$ as compared with normal desorption, resulting in isotherms that were in line with results from the field experiment. These results suggest that the drying-wetting cycles are a key factor in the long-term adsorption and desorption processes under field conditions. Third, the new approach of batch desorption experiments that allow the fast and careful complete drying of soil suspensions appears to be an appropriate method to assess sorption behaviour of herbicides over a long time period.
\end{abstract}

diuron / soil moisture / adsorption / desorption / Mediterranean climate

\section{INTRODUCTION}

Sorption-desorption interactions of herbicides with soil are the main processes that control the amounts of herbicides available for leaching, runoff and biodegradation. Therefore, predicting the fate and transport of herbicidal compounds in natural environments strongly depends on the correct assessment of the herbicide sorption behaviour in the field.

Sorption of herbicides to soil components has been extensively studied by the classical batch-equilibration method, based on the shaking of soil material and a herbicide solution for a determined time, that is 24 hours in most cases. This technique does not reflect field conditions properly since slurry conditions greatly exceed soil hydration levels encountered in field soils. The batch technique has often been recognised as insufficient to derive the actual field sorption parameters (Gaillardon and Dur, 1995; Kookana et al., 1992; Louchart et al., 2000; Pignatello and Huang, 1991). Long-term experiments have shown an increase in pesticide sorption with residence time in soil mainly due to a limited desorption from the soil (Barriuso et al., 1992; Beigel et al., 1997; Cox et al., 1998; Gaillardon, 1997; Lehmann et al., 1990; Scribner et al., 1992). This increase in the pesticide fraction resistant to desorption may result from the slow diffusion of pesticides out of the soil organic matter and/or from the entrapment of the organic com- pounds within very small pores, generally nanometer-size voids or cavities (Huang and Weber, 1997; LeBoeuf and Weber, 1997; Lu and Pignatello, 2002; Luthy et al., 1997; Pignatello and Xing, 1996; Weber et al., 2001; Xing and Pignatello, 1997). Other techniques have been developed to study sorption of organic compounds to soils and the influence of soil moisture or the solution to soil ratio, including the flow technique (Kookana et al., 1992), the miscible-displacement method (Brusseau et al., 1991; Gamerdinger et al., 1991) and the thin-disc flow method (Miller et al., 1989; Smith et al., 2003), extraction of soil solution from unsaturated soil samples by pressure (Scott and Lutz, 1971), suction (Green and Obien, 1969), centrifugation (Adams et al., 1980), or selective extraction of the pesticide from the soil solution by supercritical fluid extraction (Berglöf et al., 2000; Rochette and Koskinen, 1998).

Water content has been shown to affect considerably the sorption behaviour of pesticides. Different authors have pointed out an increase in pesticide bioavailability and extractability with an increase in soil moisture (Gaillardon, 1996; Gaillardon and Dur, 1995; García-Valcárcel and Tadeo, 1999; Scott and Lutz, 1971) or with soil saturation (Rutherford and Chiou, 1992). On the contrary, Berglöf et al. (2000) reported that sorption coefficients (Kd) of linuron slightly increased with an increasing soil water content, if less than saturated, and Gamble et al. (2000) concluded that wetting of soil favoured

\footnotetext{
* Corresponding author: xavier.louchart@ensam.inra.fr
} 
Table I. Selected soil properties $(0-5 \mathrm{~cm})$.

\begin{tabular}{ccccccc}
\hline Bulk density $\left(\mathrm{g} \mathrm{cm}^{3}\right)$ & $\mathrm{pH}\left(\mathrm{H}_{2} \mathrm{O}\right)$ & Organic $\mathrm{C}(\%)$ & Clay $0-2 \mu \mathrm{m}(\%)$ & Silt 2-50 $\mu \mathrm{m}(\%)$ & Sand 50-2000 $\mu \mathrm{m}(\%)$ & $\mathrm{CaCO}_{3}(\%)$ \\
\hline 1.44 & 8.5 & 1.06 & 18.6 & 55.4 & 26.0 & 24.0 \\
\hline
\end{tabular}

the formation of bound residues of chlorothalonil in a quartz sandy soil. The effect of initial water content on sorption behaviour was investigated by Altfelder et al. (1999). They reported that initially air-dried soil increased sorption of chlortoluron and accentuated the desorption hysteresis. Nevertheless, information on the effects of the drying and wetting cycles of soil on adsorption and desorption interactions of herbicidal compounds is very limited. It can be expected that frequent and rapid changes in soil moisture are important in long-term sorption of herbicides, especially under semi-arid and Mediterranean climates, when topsoil moisture content can regularly and rapidly drop to under $10 \%$ between rainfall events (Lennartz et al., 1997; Louchart et al., 2000; Louchart et al., 2001). Previous studies have shown that soil subjected to drying and wetting cycles resulted in increased sorption of pesticides and therefore in higher Kd values (García-Valcárcel and Tadeo, 1999; Goetz et al., 1986; Shelton et al., 1995; White et al., 1998). However, it remains unclear to what extent the soil moisture dynamic regulates the release of adsorbed herbicidal compounds.

The aim of this study was to assess the adsorption and desorption behaviour of diuron in soil as affected by soil-drying. The specific objectives were (1) to study the effect of soil drying on the desorption of diuron with a modified batch experiment approach that allowed the fast and careful complete drying of soil suspensions, (2) to analyse the evolution of diuron sorption behaviour in the field under Mediterranean climate conditions, and (3) to compare the results from laboratory studies with those from the field.

\section{MATERIALS AND METHODS}

\subsection{Herbicide characteristics}

The herbicide studied was diuron (3-(3,4-dichlorophenyl)1,1-dimethyurea) because it is one of the most frequently used in vineyards in southern France for weeding control during the spring period. At the experimental field site, diuron was applied annually as a suspension of water and oil (surfactant) by using the commercial products Trevi 10 or Vegepron DS over the study period (1995-1999). All batch experiments were carried out with the technical grade of the compound (chemical purity $>99 \%$ ).

\subsection{Field experiment}

The fate and transport of diuron was monitored over four vinegrowing seasons $(1995,1997,1998$ and 1999) on a 0.12-ha vineyard located in southern France (4330' N, $\left.3^{\circ} 19^{\prime} \mathrm{E}\right), 60 \mathrm{~km}$ west of Montpellier (Hérault). The soil of the site was classified according to FAO soil classification as a calcaric cambisol

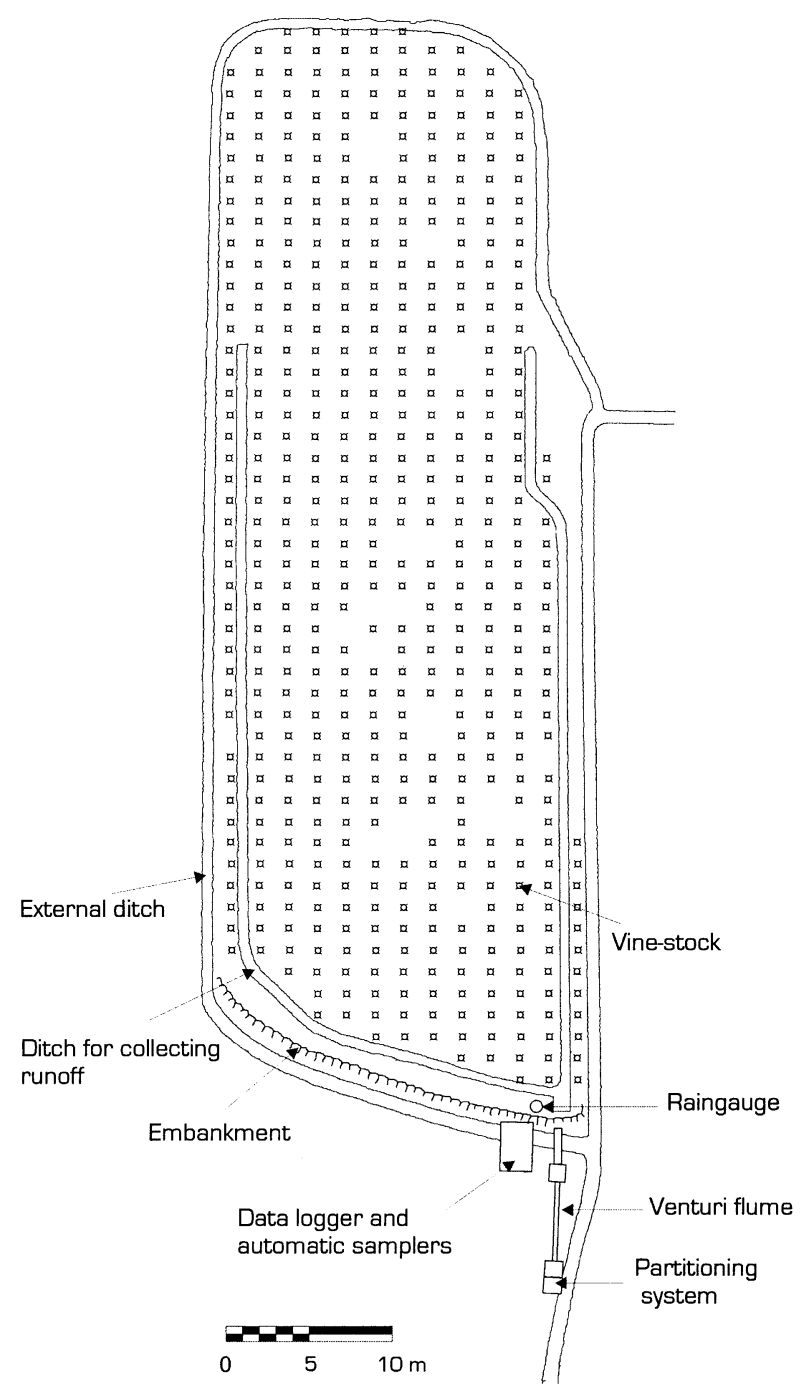

Figure 1. Experimental field site.

(FAO-UNESCO, 1989). The main soil properties are listed in Table I.

Diuron was applied manually over the entire soil surface at a rate of $1.3 \mathrm{~kg} \mathrm{ha}^{-1}$ (4 April 1995), $1.35 \mathrm{~kg} \mathrm{ha}^{-1}$ (7 April 1997), $1.45 \mathrm{~kg} \mathrm{ha}^{-1}$ (12 March 1998), and $2.23 \mathrm{~kg} \mathrm{ha}^{-1}$ (17 March 1999). During the study period, the diuron content of the soil surface layer $(0-2 \mathrm{~cm})$ and diuron concentrations in runoff water at the outlet of the field (Fig. 1) were monitored. Detailed characteristics of the field devices, soil sampling strategies, hydrological monitoring, and water sampling can be found elsewhere (Lennartz et al., 1997; Louchart et al., 2001). The 
data observed were used to estimate: (1) the event average concentration of diuron concentration in runoff water, including both diuron in the dissolved and solid (sediment) phases of the runoff water, and (2) the average diuron content of the topsoil at the time of each runoff event by linear interpolation between the soil sampling dates. Altogether, the experiments provided a set of 62 pairs of diuron concentrations in soil and runoff water.

\subsection{Batch experiments}

Soil used for the batch experiments was collected from the topsoil of the experimental vineyard. Two series of batch experiments were performed.

In the first series, a classical sorption experiment with one adsorption and three successive desorption steps using five initial concentrations $\left(0.05,0.2,0.5,2\right.$ and $\left.5 \mathrm{mg} \mathrm{L}^{-1}\right)$ was conducted. For the adsorption step, five grams of air-dried soil were dispersed in $25 \mathrm{~mL}$ of diuron solution and shaken in PTFE-containers in an overhead shaker for $24 \mathrm{~h}$. Thereafter, desorption was initiated by removing $20 \mathrm{~mL}$ of the solution for diuron analysis and replacing it with the same volume of chemical-free $0.01 \mathrm{M} \mathrm{CaCl}{ }_{2}$ solution. The procedure was repeated twice for the second and third desorption steps.

The second series consisted of a set of sorption experiments where the soil suspension was completely dried either once (before the first desorption step) or three times (before each desorption step). After the removal of $20 \mathrm{~mL}$ of solution for diuron analysis, a procedure for evaporating the remaining $5 \mathrm{~mL}$ had to be established since extraction in liquid form (e.g. by syringe or pipette) was impossible. Thermal ovens with or without climate regulation options were found not to be suitable because of the unacceptable heating of samples above $35^{\circ} \mathrm{C}$ or because of the required time. Microwave ovens have been identified earlier as a suitable tool for the drying of soil samples. Water molecules are bound to polar soil components which directly absorb the microwave energy. Heat energy transfer to nonpolar soil constituents occurs by convection and conduction. As long as the amount of absorbed microwave energy is small compared with the energy required for evaporation, no modification of soil components, especially of the organic matter, can be expected. In the case that the added energy is greater than what is needed for vaporisation, the organic soil constituents can be oxidised or water can be bound within the mineral particles, which is therewith part of the soil solid fraction. The major issue for a reasonable use of the microwave technique for the drying of soil samples is to find the exact relation between microwave energy added to the soil/water system and the optimum time period in order to avoid over-drying. The microwave oven MLS-1200MEGA240 from MLS GmbH/ MILESTONE used in this study allows energy adjustment in $10 \mathrm{Watt}$ steps. Pre-tests showed that a power of $70 \mathrm{Watt}$ is sufficient for the vaporisation of the remaining water within $5 \mathrm{~h}$. The constantly controlled temperature did not increase above $35^{\circ} \mathrm{C}$. Desorption with drying cycles were carried out with two initial concentrations $\left(0.2\right.$ and $\left.2 \mathrm{mg} \mathrm{L}^{-1}\right)$. For each sample set, adsorption and desorption experiments were conducted with three replicates. The data presented hereafter are the average values.

\subsection{Analytical procedures}

For the batch experiment, the diuron concentration of water samples was analysed by using a High Performance Liquid Chromatography (HPLC) system with an integrated on-line sample preparation (RP-HPLC). An aliquot of $5 \mathrm{~mL}$ of the water samples was directly injected into the preparation cycle of the system, consisting of a column-switch-module (Merck OSP-2A) and a pump (Kontron System 325). The herbicidal compound was enriched on Merck HPLC guard columns (LiChrospher 100; RP-18, $5 \mu \mathrm{m}$ ). Samples were quantitatively eluted from the guard columns into the analytical cycle of the system. Two reagent pumps were used to adjust the flow rate of the mobile phase (isocratic $70 \%$ acetonetrile, $30 \%$ water) at

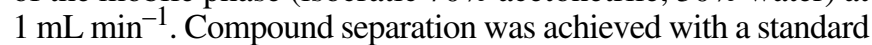
RP-18 separation column (Kontron Spheri-5 RP-18 2204.6 mm i.d.). The subsequent detection of the chemicals was performed at $242 \mathrm{~nm}$ with an UV-VIS detector (Kontron 430).

For the field experiment, soil and water samples, filtered at $0.45 \mu \mathrm{m}$, were stored frozen at $-20{ }^{\circ} \mathrm{C}$ until analysis at the INRA Soil Analysis Laboratory of Arras. Detailed procedures of the extraction are described in Louchart et al. (2001). Diuron concentrations were analysed with a Varian HPLC system (compound pump model 9012, autosampler model 9100 and ultraviolet diode array detector model 9065). Separation of analytes was performed on a Kromasil $100 \mathrm{C} 18-5 \mu \mathrm{m}$ column (25054.6 $\mathrm{mm}$ i.d.). The initial mobile phase was $80 \%$ MilliQ water, $20 \%$ acetonitrile. During the 45 -min run of each sample the ratio of solvents was changed with a linear gradient to $10 \%$ MilliQ water and $90 \%$ acetonitrile reached after a 35-min run. The flow rate was $1 \mathrm{~mL} \mathrm{m^{-1 }}$ and the injected volume was $100 \mu \mathrm{L}$. Maximum absorption of diuron was identified at a wavelength of $249 \mathrm{~nm}$ and retention time was 18.42 minutes. The detection limits were $0.8 \mu \mathrm{g} \mathrm{kg}^{-1}$ for soil samples and $0.1 \mu \mathrm{g} \mathrm{L}{ }^{-1}$ for water samples.

\subsection{Calculations}

The batch adsorption isotherm was obtained by plotting the amount of adsorbed diuron vs. equilibrium concentration of diuron in solution for the five initial concentrations $(0.05,0.2$, $0.5,2$ and $5 \mathrm{mg} \mathrm{L}^{-1}$ ). The two batch desorption isotherms (from the initially adsorbed diuron for the 0.2 and $2 \mathrm{mg} \mathrm{L}^{-1}$ trials) were obtained by plotting the amount of adsorbed diuron vs. equilibrium concentration of diuron in solution after each desorption step (repeated three times).

Desorption isotherms from the field experiment were estimated by comparing diuron contents in the topsoil remaining after the runoff event ( $\mathrm{S}$ in $\mathrm{mg} \mathrm{kg}^{-1}$ of dry soil) vs. diuron concentrations in runoff water $\left(\mathrm{C}\right.$ in $\left.\mathrm{mg} \mathrm{L}^{-1}\right)$. The following mass balance equation was used to calculate the $S$ values:

$\mathrm{m} \mathrm{M}=\mathrm{m} \mathrm{S}+\mathrm{V} \mathrm{C}$, where $\mathrm{M}\left(\mathrm{mg} \mathrm{kg}^{-1}\right.$ of dry soil) is the estimated diuron content in soil before the runoff event (estimation by linear interpolation from the measured values), $\mathrm{m}(\mathrm{kg})$ is the soil mass of the surface layer $(0-2 \mathrm{~cm})$, and V (L) is the total runoff volume of the event. The plot of $\mathrm{S}$ values vs. $\mathrm{C}$ values were interpreted as field-desorption isotherms, where each runoff event corresponds to a desorption step. This interpretation is based on the hypothesis that desorption is the main process of extraction of diuron adsorbed onto the soil by runoff water 


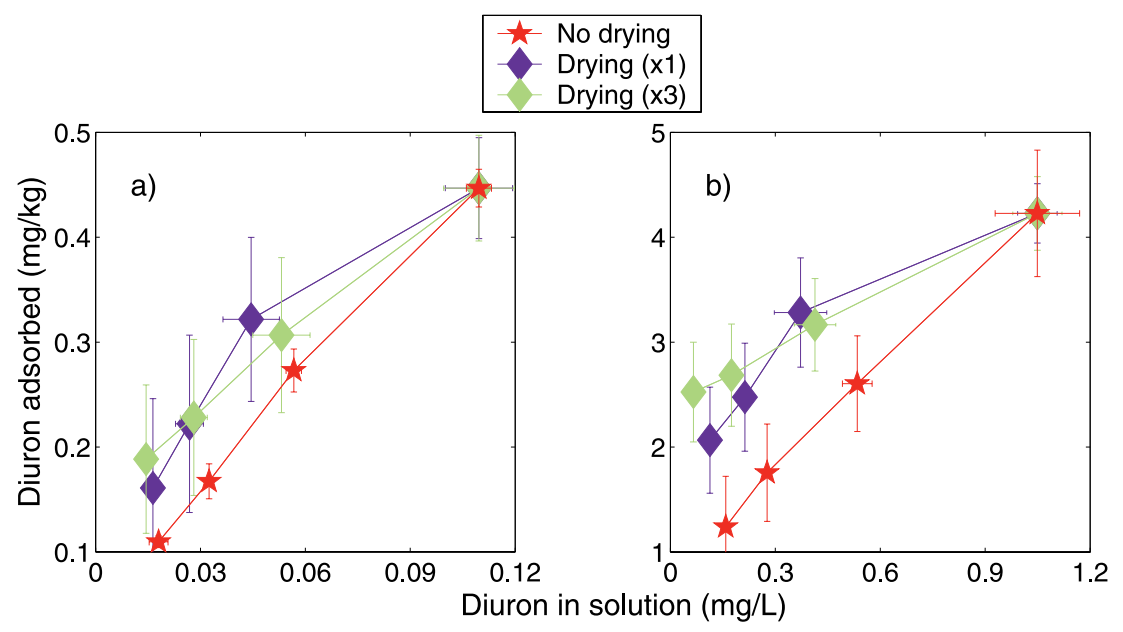

Figure 2. Sorption isotherms from batch experiments with and without drying cycles for initial concentrations of $0.2 \mathrm{mg} \mathrm{L}^{-1}$ (a) and $2 \mathrm{mg} \mathrm{L}^{-1}$ (b).

Table II. Freundlich parameter values (95\% confidence interval) of the various ad- and desorption isotherms with or without drying cycles. $\mathrm{r}^{2}$ is the coefficient of determination.

\begin{tabular}{|c|c|c|c|c|}
\hline & Initial concentration $\left(\mathrm{mg} \mathrm{L}^{-1}\right)$ & $\mathrm{K}_{\mathrm{f}}$ & $\mathrm{nf}$ & $\mathrm{r}^{2}$ \\
\hline \multirow[t]{3}{*}{ Adsorption } & & $4.08(0.37)$ & $1.21(0.087)$ & 1 \\
\hline & 0.05 & $13.72(82.73)$ & $1.593(1.754)$ & 0.958 \\
\hline & 0.2 & $2.54(0.56)$ & $0.784(0.086)$ & 0.999 \\
\hline \multirow[t]{3}{*}{ Normal desorption } & 0.5 & $3.3(1.37)$ & $0.925(0.255)$ & 0.995 \\
\hline & 2 & $4.07(0.26)$ & $0.663(0.097)$ & 0.998 \\
\hline & 5 & $9.32(1.57)$ & $0.436(0.201)$ & 0.98 \\
\hline Desorption with & 0.2 & $1.31(0.95)$ & $0.494(0.267)$ & 0.972 \\
\hline 1 drying cycle & 2 & $4.16(0.58)$ & $0.318(0.143)$ & 0.979 \\
\hline Desorption with & 0.2 & $1.31(0.95)$ & $0.458(0.149)$ & 0.99 \\
\hline 3 drying cycles & 2 & $4.16(0.58)$ & $0.205(0.176)$ & 0.927 \\
\hline
\end{tabular}

(Louchart, 1999). This implies that a chemical may be transferred to runoff from a soil depth as great as $2 \mathrm{~cm}$. It has been shown experimentally that the effective interaction between soil, rain and runoff water varies between a few $\mathrm{mm}$ and $3 \mathrm{~cm}$ (Ahuja et al., 1981; Havis et al., 1992; Ingram and Woolhiser, 1980; Sharpley, 1995; Zhang et al., 1997), although chemical extraction by rainwater and overland flow decreases with depth (Heathman et al., 1986).

\section{RESULTS AND DISCUSSION}

\subsection{Isotherms from batch experiments}

The Freundlich sorption isotherm $S=K_{f} C^{n f}$, where $K_{f}$ and nf are the Freundlich coefficient and exponent, respectively, was fitted to the experimental data for the adsorption and desorption experiments. Table II gives the results along with the coefficient of determination $\left(\mathrm{r}^{2}\right)$.

The adsorption isotherm of diuron had an exponent larger than 1 (Tab. II), while the desorption branches exhibited Freund- lich exponents of less than 1 in all cases, revealing a hysteretic sorption-desorption behaviour of diuron under the chosen experimental conditions (excluding the lowest concentration which had a high error and therefore is considered unreliable). The hysteretic effect was more pronounced for the greater initial concentration which resulted in an increase in $\mathrm{K}_{\mathrm{f}}$ values and a decrease in nf exponents. The values of the desorption coefficient $\mathrm{K}_{\mathrm{f}}$ were of the same order of magnitude as those reported in previous studies with diuron (Gaillardon, 1996, 1997; Gaillardon and Dur, 1995). Our results are in line with the work reported by Gaillardon (1996) and show that at large initial herbicide concentrations the irreversible bound chemical fraction is more important.

The results of desorption with 1 or 3 drying cycles are presented in Table II, and isotherms are compared with those of the classical desorption procedure in Figure 2. In all cases, drying of the soil clearly affected the desorption capabilities of diuron. Depending on the initial concentration and the number of drying cycles, the Freundlich exponent was 1.6 to 3 times smaller than in the case of normal desorption. After 3 desorption-drying steps, it was only possible to desorb 59\% and $41 \%$ 
Table III. Optimized Freundlich parameters (95\% confidence interval) of the equivalent (field) desorption isotherm of diuron residues in soil vs. diuron concentrations in runoff water. $\mathrm{r}^{2}$ is the coefficient of determination.

\begin{tabular}{lccc}
\hline Year & $\mathrm{K}_{\mathrm{f}}$ & $\mathrm{nf}$ & $\mathrm{r}^{2}$ \\
\hline 1995 & $6.57(2.29)$ & $0.539(0.177)$ & 0.893 \\
1997 & $2.37(0.46)$ & $0.369(0.093)$ & 0.861 \\
1998 & $3.78(0.79)$ & $0.441(0.138)$ & 0.932 \\
1999 & $3.58(0.24)$ & $0.562(0.034)$ & 0.993 \\
All & $3.39(0.49)$ & $0.418(0.074)$ & 0.80 \\
\hline
\end{tabular}

of the initially adsorbed diuron for the 0.2 and $2 \mathrm{mg} \mathrm{L}^{-1}$ trials, respectively. Whereas, after 3 desorption steps with no drying, more than $70 \%$ of the initially adsorbed diuron in soil could be desorbed. The difference in the desorbed chemical amount as caused by the drying procedure corresponds to results obtained with 2,4-D (Sharer et al., 2003), simazine (Scribner et al., 1992) and atrazine (Barriuso et al., 1992) from field desorption experiments, where the investigated chemicals were exposed to the soil for time periods varying from a few months to a few years. It seems that the technique of drying the samples in between desorption steps resulted in an "aging effect" mirroring the dynamic of herbicide-soil interactions under field conditions over long time periods. The presented method may be considered as a fast technique that could help with assessing long-term sorption effects that up to now could only be investigated using time- and resource-intensive field studies.

Desorption isotherms from batch experiments exhibited hysteresis that was more pronounced when the soil was dried at least one time before desorption. Hysteresis is often assumed to be caused by slow sorption (Brusseau and Rao, 1989) which prevents sorption equilibrium occurring within the time period of the experiment. Slow sorption may be diffusion-limited and responsible mechanisms could be identified as diffusion through natural soil organic matter and diffusion through intraparticle nanopores (Pignatello and Xing, 1996). Based on these results and on previous works or critical reviews (Huang and Weber, 1997; LeBoeuf and Weber, 1997; Lu and Pignatello, 2002; Luthy et al., 1997; Pignatello and Xing, 1996; Weber et al., 2001; Xing and Pignatello, 1997), we assume that drying causes extensive changes in the structure of soil organic matter, reducing the accessibility of internal nanopores for the desorption of diuron and therefore increasing the entrapment of diuron within the soil organic matter. There is experimental evidence that these changes are not completely irreversible, but the wetting process of dried soil organic matter has slow kinetics (Altfelder et al., 1999; Belliveau et al., 2000) and the time to reach the initial state and approach equilibrium may exceed several days or months (Miller and Pedit, 1992; Pignatello and Xing, 1996).

\subsection{Isotherms from field experiment}

The desorption isotherms derived from the field experiment are shown in Figure 3 and the obtained Freundlich parameters are presented in Table III. It should be noted that the large number of monitored runoff events allowed assessment of the

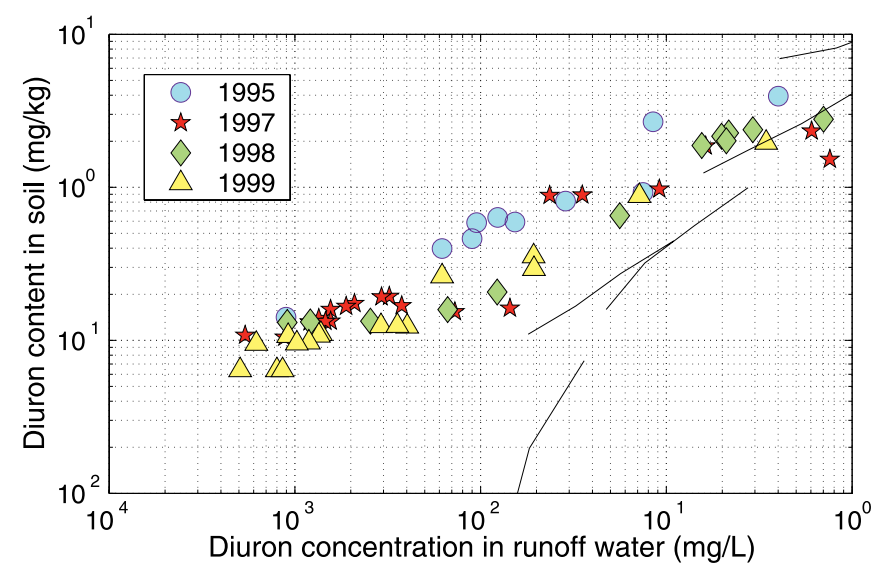

Figure 3. Diuron residues in soil vs. diuron concentrations in runoff water for the four years studied along with isotherms from classical desorption tests. Black lines are the standard batch desorption isotherms (without drying cycles) for the five initial concentrations.

variation of diuron sorption over a large range of concentrations. These concentrations covered the range investigated in the laboratory desorption experiments with initial diuron solutions of 0.2 and $2 \mathrm{mg} \mathrm{L}^{-1}$ allowing the comparability of the field- and batch-derived isotherms.

The isotherms (Fig. 3) and parameters (Tab. III) obtained for the four years were quite similar, indicating a relative stability of the year-to-year partition between diuron residues in soil and diuron concentrations in runoff water. Furthermore, $\mathrm{K}_{\mathrm{f}}$ values and exponents were close to those obtained from desorption experiments with 1 or 3 drying cycles (Tab. II). The continuity and the good agreement of model parameter values suggest that: (1) soil drying and wetting cycles after herbicide application are important factors for the long-term sorption behaviour of diuron under Mediterranean climate conditions. Rapid changes in soil moisture to extreme values due to high evaporation or heavy rainfall appears therefore to be more important for adsorption and desorption processes than the annual variability of cumulative rainfall, number of runoff events, and rate of diuron application, and (2) the presented new approach of including drying and wetting cycles in classical adsorption and desorption experiments may be appropriate for evaluating field sorption behaviour of herbicides.

\section{CONCLUSION}

An increase in sorption of diuron (11\% to $29 \%$ depending on the initial concentration of diuron for the batch adsorption - desorption experiments) was observed when soil was dried before a desorption step. The hysteresis for desorption isotherms was also more pronounced than with classical batch desorption, revealing that attainment of equilibrium should take more time. From this finding it can be assumed that drying and wetting cycles in batch desorption experiments may accentuate the diffusion processes implied in slow sorption phenomena. The desorption isotherms obtained from the batch experiment including drying-wetting cycles were close to those derived 
from the field experiment over a long time period. This good agreement suggests that soil drought plays a major role in modifying the sorption behaviour of pesticides in soil and therefore their availability to transfer by overland flow or infiltration. The drying-wetting cycles should be considered in further studies as an influential factor on long-term sorption in the same way as soil type, temperature, agronomic practices, etc.

The new approach of batch desorption experiments that allow the fast and careful complete drying of soil suspensions appears to be an appropriate method to assess sorption behaviour of herbicides over a long time period. The validity of the derived sorption parameters for pesticide runoff transport modelling is currently being examined.

Acknowledgements: This research work was supported by INRA ("AIP Eau" and "AIP Pesticides" project) and EGIDE ("PAI Procope" project). The authors thank the INRA Laboratory of Soil Analyses in Arras and the Institute of Soil Science at Rostock University for complete diuron analyses in soil and water samples.

\section{REFERENCES}

Adams F., Burmester C., Hue N.V., Long F.L. (1980) A comparison of column-displacement and centrifuge methods for obtaining soil solutions, Soil Sci. Soc. Am. J. 44, 733-735.

Ahuja L.R., Sharpley A.N., Yamamoto M., Menzel R.G. (1981) The depth of rainfall-runoff-soil interaction as determined by $32 \mathrm{P}$, Water Resour. Res. 17, 969-974.

Altfelder S., Streck T., Richter J. (1999) Effect of air-drying on sorption kinetics of the herbicide chlortoluron in soil, J. Environ. Qual. 28, $1154-1161$.

Barriuso E., Koskinen W.C., Sorenson B. (1992) Modification of atrazine desorption during field incubation experiments, Sci. Total Environ. 123/124, 333-344.

Beigel C., Barriuso E., Di Pietro L. (1997) Time dependency of triticonazole fungicide sorption and consequences for diffusion in soil, $\mathrm{J}$. Environ. Qual. 26, 1503-1510.

Belliveau S.M., Henselwood T.L., Langford C.H. (2000) Soil Wetting Processes Studied by Magnetic Resonance Imaging: Correlated Study of Contaminant Uptake, Environ. Sci. Technol. 34, 24392445.

Berglöf T., Koskinen W.C., Brücher J., Kylin H. (2000) Linuron Sorption-Desorption in Field-Moist Soils, J. Agr. Food Chem. 48, 37183721.

Brusseau M.L., Rao P.S.C. (1989) Sorption nonideality during organic contaminant transport in porous media, Crit. Rev. Environ. Control $19,33-99$.

Brusseau M.L., Jessup R.E., Rao P.S.C. (1991) Nonequilibrium sorption of organic chemicals: elucidation of rate-limiting processes, Environ. Sci. Technol. 25, 134-142.

Cox L., Koskinen W.C., Yen P.Y. (1998) Changes in sorption of imidachloprid with incubation time, Soil Sci. Soc. Am. J. 62, 342-347.

FAO-UNESCO (1989) Soil map of the world at 1:5 000 000, 2nd ed., Food and Agriculrure Organization, Rome.

Gaillardon P. (1996) Influence of soil moisture on long-term sorption of diuron and isoproturon by soil, Pestic. Sci. 47, 347-354.

Gaillardon P. (1997) Desorption of diuron and isoproturon from undispersed clay loam soil, Pestic. Sci. 51, 185-193.

Gaillardon P., Dur J.C. (1995) Influence of soil moisture on short-term adsorption of diuron and isoproturon by soil, Pestic. Sci. 45, $297-$ 303.
Gamble D.S., Bruccoleri A.G., Lindsay E., Langford C.H., Leyes G.A. (2000) Chlorothalonil in a Quartz Sand Soil: Wetting Effects on Sorption Capacity and Bound Residue, Environ. Sci. Technol. 34, 125-129.

Gamerdinger A.P., Lemley A.T., Wagenet R.J. (1991) Nonequilibrium sorption and degradation of three 2-chloro-s-triazine herbicides in soil-water systems, J. Environ. Qual. 20, 815-822.

García-Valcárcel A.I., Tadeo J.L. (1999) Influence of Soil Moisture on Sorption and Degradation of Hexazinone and Simazine in Soil, J. Agr. Food Chem. 49, 3895-3900.

Goetz A.J., Wehtje G., Walker R.H., Hajek B. (1986) Soil solution and mobility characterization of imazaquin, Weed Sci. 34, 788-793.

Green R.E., Obien S.R. (1969) Herbicide equilibrium in soils in relation to soil water content, Weed Sci. 17, 514-519.

Havis R.N., Smith R.E., Adrian D.D. (1992) Partitioning solute transport between infiltration and overland flow under rainfall, Water Resour. Res. 28, 2569-2580.

Heathman G.C., Ahuja L.R., Baker J.L. (1986) Test of a Non-Uniform Mixing Model for Transfer of Herbicides to Surface Runoff, Trans. ASAE 29, 450-455.

Huang W., Weber W.J. (1997) A Distributed Reactivity Model for Sorption by Soils and Sediments. 10. Relationships between Desorption, Hysteresis, and the Chemical Characteristics of Organic Domains, Environ. Sci. Technol. 31, 2562-2569.

Ingram J.J., Woolhiser D.A. (1980), Chemical transfer into overland flow, in Proceedings Symposium on Watersheds Management' 80 , Boise, Idaho, July 21-23, 1980.

Kookana R.S., Aylmore L.A.G., Gerritse R.G. (1992) Time-dependent sorption of pesticides during transport in soils, Soil Sci. 154, 214225.

LeBoeuf E.J., Weber W.J. (1997) A Distributed Reactivity Model for Sorption by Soils and Sediments. 8. Sorbent Organic Domains: Discovery of a Humic Acid Glass Transition and an Argument for a Polymer-Based Model, Environ. Sci. Technol. 31, 1697-1702.

Lehmann R.G., Miller J.R., Laskowski D.A. (1990) Fate of fluoxypyr in soil: II. Desorption as a function of incubation time, Weed Res. 30, 383-388.

Lennartz B., Louchart X., Andrieux P., Voltz M. (1997) Diuron and simazine losses to runoff water in mediterranean vineyards, J. Environ. Qual. 26, 1493-1502.

Louchart X. (1999) Transfert de pesticides dans les eaux de surface aux échelles de la parcelle et d'un bassin versant viticole. Étude expérimentale et éléments de modélisation. Thèse de doctorat, Ecole Nationale Supérieure Agronomique de Montpellier, Montpellier.

Louchart X., Voltz M., Andrieux P. (2000) Temporal variation in the availability of diuron to transport by overland flow, C.R. Acad. Sci., Sér. III-Sciences de la Vie 331, 475-481.

Louchart X., Voltz M., Andrieux P., Moussa R. (2001) Herbicides runoff at field and watershed scales in a Mediterranean vineyard area, J. Environ. Qual. 30, 982-991.

Lu Y., Pignatello J.J. (2002) Demonstration of the "Conditioning Effect" in Soil Organic Matter in Support of a Pore Deformation Mechanism for Sorption Hysteresis, Environ. Sci. Technol. 36, 4553 4561

Luthy R.G., Aiken G.R., Brusseau M.L., Cunningham S.D., Gschwend P.M., Pignatello J.J., Reinhard M., Traina S.J., Weber W.J., Westall J.C. (1997) Sequestration of Hydrophobic Organic Contaminants by Geosorbents, Environ. Sci. Technol. 31, 3341-3347.

Miller C.T., Pedit J.A. (1992) Use of a reactive surface-diffusion model to describe apparent sorption-desorption hysteresis and abiotic degradation of lindane in a subsurface material, Environ. Sci. Technol. $26,1417-1427$.

Miller D.M., Summer M.E., Miller W.P. (1989) A comparison of batchand flow-generated anion adsorption, Soil Sci. Soc. Am. J. 53, 373 380. 
Pignatello J.J., Huang L.Q. (1991) Sorptive reversibility of atrazine and metolachlor residues in field soil samples, J. Environ. Qual. 20, 222-228.

Pignatello J.J., Xing B. (1996) Mechanisms of slow sorption of organic chemicals to natural particles, Environ. Sci. Technol. 30, 1-11.

Rochette E.A., Koskinen W.C. (1998) Atrazine sorption in field-moist soils: supercritical carbon dioxide density effects, Chemosphere 36 , $1825-1839$.

Rutherford D.W., Chiou C.T. (1992) Effect of water saturation in soil organic matter on the partition of organic compounds, Environ. Sci. Technol. 26, 965-970.

Scott H.D., Lutz J.F. (1971) Release of herbicides from clay minerals as a function of water content: I. Kaolinite, Soil Sci. Soc. Am. J. 35, 374-379.

Scribner S.L., Benzing T.R., Sun S., Boyd S.A. (1992) Desorption and bioavailability of aged simazine residues in soil from a continuous corn field, J. Environ. Qual. 21, 115-120.

Sharer M., Park J.-H., Voice T.C., Boyd S.A. (2003) Aging effects on the sorption-desorption characteristics of anthropogenic organic compounds in soil, J. Environ. Qual. 32, 1385-1392.
Sharpley A.N. (1995) Dependence of runoff phosphorus on extractable soil phosphorus, J. Environ. Qual. 24, 920-926.

Shelton D.R., Sadeghi A.M., Karns J.S., Hapeman C.Y. (1995) Effect of wetting and drying of soil on sorption and biodegradation of atrazine, Weed Sci. 43, 298-305.

Smith M.C., Shaw D.R., Massey J.H., Boyette M., Kingery W. (2003) Using nonequilibrium thin-disc and batch equilibrium techniques to evaluate herbicide sorption, J. Environ. Qual. 32, 1393-1404.

Weber W.J., LeBoeuf E.J., Young T.M., Huang W. (2001) Contaminant interactions with geosorbent organic matter: insights drawn from polymer sciences, Water Res. 35, 853-868.

White J.C., Quinones-Rivera A., Alexander M. (1998) Effect of wetting and drying on the bioavailability of organic compounds sequestred in soil, Environ. Toxicol. Chem. 17, 2378-2382.

Xing B., Pignatello J.J. (1997) Dual-Mode Sorption of Low-Polarity Compounds in Glassy Poly(Vinyl Chloride) and Soil Organic Matter, Environ. Sci. Technol. 31, 792-799.

Zhang X.C., Norton L.D., Hickman M. (1997) Rain pattern and soil moisture content effects on atrazine and metolachlor losses on runoff, J. Environ. Qual. 26, 1539-1547. 